\title{
INFLUENCE OF DIE VIBRATION ON FRICTION IN UPSET-FORGING OF SMALL COMPONENTS
}

\author{
${ }^{1}$ Wojciech PRESZ, ${ }^{2}$ Jinming SHA, ${ }^{1}$ Bjarne RAVN, ${ }^{2}$ Tarras WANHEIM \\ ${ }^{1}$ Warsaw University of Technology, Institute of Material Processing, Warsaw, Poland, EU \\ w.presz@wip.pw.edu.pl \\ ${ }^{2}$ Technical University of Denmark, Lyngby, Denmark, EU
}

https://doi.org/10.37904/metal.2019.702

\begin{abstract}
This paper deals with the influence of die surface orientation of roughness and die surface excitation on friction in metal forming processes. A way to evaluate friction coefficients from the flattening of long rectangular specimen was used for aluminium specimens with different die surface orientation of roughness. At the same time, this method was also used to examine the influence of die surface lateral vibration to friction with different parameters, such as frequency, amplitude and orientation of the specimen. The experimental results show that the roughness and die vibration have significant effects on friction in bulk forming process of small components.
\end{abstract}

Keywords: Friction test, die vibration, surface roughness and upsetting

\section{INTRODUCTION}

The history of vibration energy assistance in metal forming processes has already been over 60 years. The first use of vibration energy to metals was reported in 1953 by Garskii, and Efromov [1]. This was followed in 1955 by Blaha and Langenecker [2] who superimposed high frequency vibrations onto the static load during tensile testing of a zinc single crystal specimen and reported a substantial reduction in the yield stress. In wire and tube drawing processes, many investigators observed a considerable stress reduction as a result of ultrasound $[3,4]$. The influence of ultrasonic oscillation on friction was first examined by Lehfeldt [5]. A ball excited by oscillation moves on a revolving plate similar to a record player needle on a record. Minimum frictional forces can be obtained when the contact surface of the oscillating body is at the maximum amplitude of movement and the oscillating direction is parallel to the moving direction. Experience and knowledge show that the reduction of forming force by introducing vibration in metal forming processes results from two reasons; one reason for the force decrease is the reduction of friction between die and work piece [6], and the other reason is the absorption of sonic energy by the lattice dislocations [7-9] or phase transformations [10] and the change of forming properties of the work piece. Despite so many works in the years 1950-1980, there are no examples of spectacular industrial applications in any of the vibration areas studied: ultrasonic and so-called "direct excitation". The reasons are to be found in energy constraints resulting from the need to introduce into vibrations large masses that are associated with the conduct of metal forming processes. The situation changed with progressive miniaturization. The development of mems, moems, micro-machines and even micro-robots is no longer futurology but the present state. These devices need a lot of metal parts with high accuracy and smoothness of the surface [11]. These requirements are met by the metal forming technology due to the possibility of creating theoretically "atomically smooth" surfaces. It is related to the creation of the product surface by plastic deformation with the elimination of cracking. However, in relation to microscopic products there are so-called "scale or size effects" that caused the emergence of new technology microforming [12]. Scale effects are related to the structure of the material (grains and phases) [13-15] and the "surface layer" [16], which is a 3-dimensional structure with a thickness depending on the material properties of the object and the history of creation of its surface $[17,18]$. In the case of micro-objects, the volume of the surface layer cannot be neglected and can affect the mechanical properties of the product. On the other hand 
the danger of galling increasis with diminishing of object size [19]. In connection with the development of the micro-device market, metal parts with volumes close to $1 \mathrm{~mm}^{3}$ and masses of several milligrams are commonly manufactured. In such cases, the energy barrier related to vibration assistance practically disappears. This is the reason for the renewed interest in such support. In the last dozen or so years, the number of works devoted to this issue has been gradually increasing [20-21]. However most of the investigation is carried out in high frequency, normally in ultrasonic frequency (above 18kHz). Less work is taking into account lower frequency (under $200 \mathrm{~Hz}$ ), [22-26]. One of the most common friction tests in forging is the ring test invented by Kunogi and Kudo and developed by Male and Cockcroft. Another method of friction test is the "cigar" test introduced by R.Hill [27] and developed for Tresca friction by D.C. Fricker and T. Wanheim [28], who used it for estimating friction conditions in model material work. Consider the upsetting of a long rectangular slab with the dimension $2 \mathrm{~b} 0: 2 \mathrm{a} 0: \mathrm{h}=20: 2: 1$ where the thickness $\mathrm{h}$ is reduced. For frictionless conditions volume constancy and isotropy mean, that the length $2 b$ and the width $2 a$ will be equally increased. With friction along the contact faces $a \times b$ the elongation will be decreased and the width increased in comparison with the frictionless case, resulting in the characteristic cigar shape. This lead Hill to propose its use for lubricant evaluation and the test became known as the "cigar test". Friction in deformation processes is dependent on surface roughness. Die surfaces are technically smooth in process such as cold extrusion, wire drawing etc. in the macro-scale. In the microforming condition the tool roughness, especially the roughness directionality resulting from the grinding process, can significantly affect material flow and contact phenomena. It is therefore possible to expect friction anisotropy caused by roughness directionality [29]. On the other hand, using the horizontal vibrations, friction anisotropy associated with the directionality of vibrations can be expected. The work piece itself is not a homogeneous, isotropic continuum but a polycrystalline body which, in the course of deformation, develops a roughness, related to grain size and surface expansion. In this work however it is assumed that these inhomogeneity might be eliminated by the prevailing lubrication mechanism. In order to investigate the anisotropy of friction parallel to and transverse to the orientation of the surface orientation and its dependence on the direction of vibration, the "cigar test" was chosen. This paper is concerned with the behaviour of a metal slab compressed plastically between paralleled rigid platens. The platens were machined with or without surface roughness orientation and the experiments were carried out with or without vibration during upsetting. The slabs were positioned at $0^{\circ}, 45^{\circ}$ and $90^{\circ}$ to the surface orientation of the platens and to the direction of vibration.

\section{THEORY REVIEW}

For liquid lubricants employed in the experiments described later, it seems reasonable to express the friction stress relationship in terms of the Amonton law of sliding friction

$$
\tau=\mu p
$$

where dimensionless $\mu$ is the usual coefficient of friction and $p(\mathrm{MPa})$ is the normal pressure between the sliding surfaces.
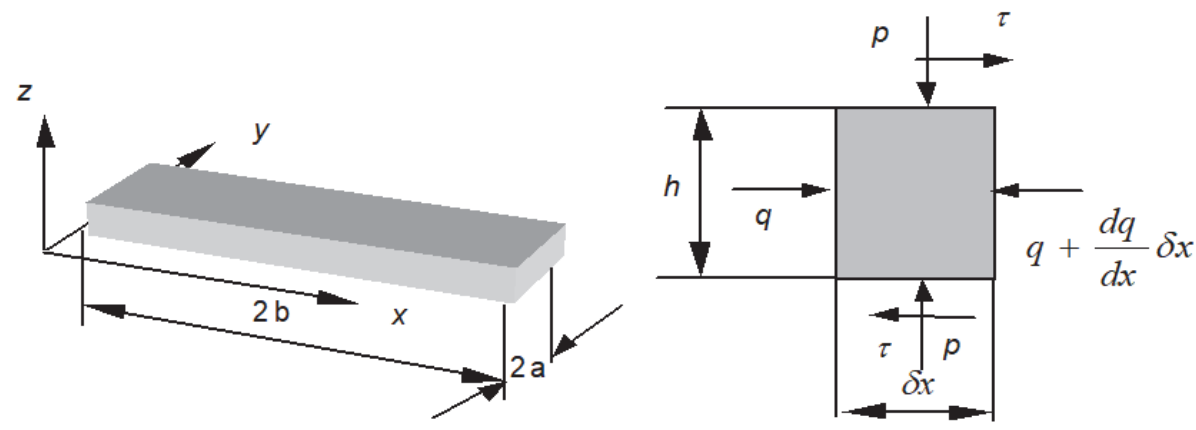

Figure 1 The co-ordinates and stress on an element of specimen 
However, there may well be a dependence of friction stress $\tau(\mathrm{MPa})$ on sliding length, surface topography and pressure-dependent lubricant properties. The co-ordinates and stresses on an element of the specimen are shown in Figure 1.

For an infinitesimally thin section in the left-hand half of the lamina, the stresses are also shown there. By using the slab method of analysis, and the Levy-Mises plastic strain-stress relationship, Hill shows that:

$\frac{b}{b_{0}}=\left(\frac{h}{h_{0}}\right)^{1 / 2}\left(1-\frac{\mu b}{2 h}\right) /\left(1-\frac{\mu b_{0}}{2 h_{0}}\right)$

When $\mu b / h<0.288$

$d b_{b}=(-d h) \frac{0.076}{\mu}$

When $\mu b / h \geq 0.288$

In the present experiments the nominal specimen were keeping the ratio of $20: 2: 1$ in dimensions, so that $b_{0} /$ $h_{0}=10$. Figure 1 shows the corresponding theoretical relation between the fractional change in length $\left(b / b_{0}-\right.$ 1 ) and the fractional reduction in height $\left(1-h / h_{0}\right)$ for various values of $\mu$. At the critical value of $b / h$, for which the centre of the slab undergoes no extension, the curve (2) is replaced by a line of slope $0.076 h_{0} / \mu b_{0}$, according to (3). When $\mu$ is greater than 0.0288 the relation is linear from the start when $b_{0} / h_{0}=10$.

\section{EXPERIMENTAL APPARATUS}

Testing equipment and techniques have been developed to explore the effects of vibration to upsetting. The tool consists of bottom plate, moving die, vibration system and measuring system (Figure 2). The bottom -1 is as well the platform for mounting other parts as the lower die.

(a)

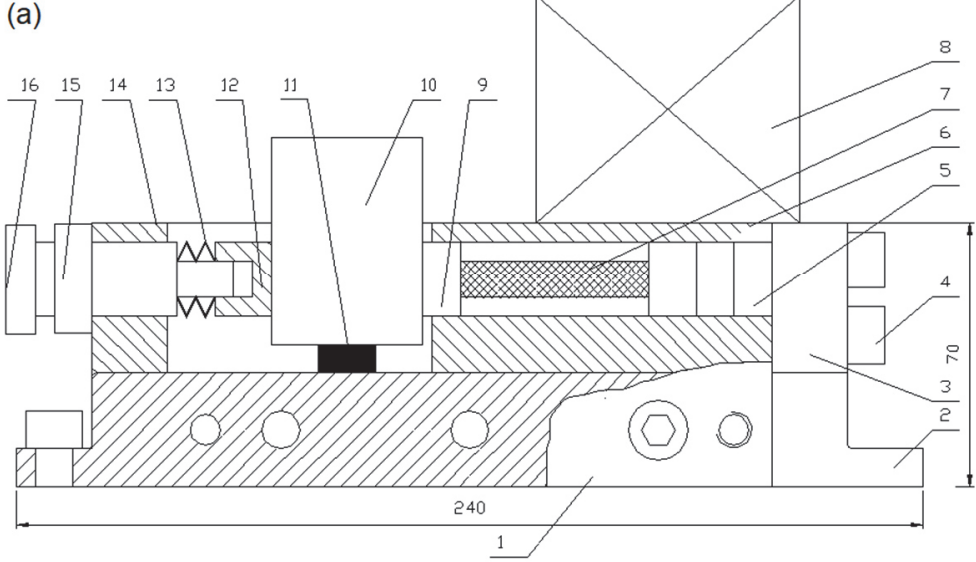

(b)

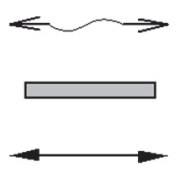

(a) $\mathrm{S} 0^{\circ}, \mathrm{D} 0^{\circ}$

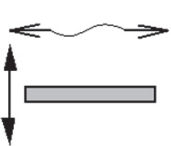

(b) $\mathrm{S} 45^{\circ}, \mathrm{D} 0^{\circ}$

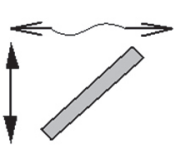

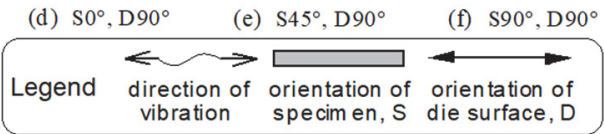

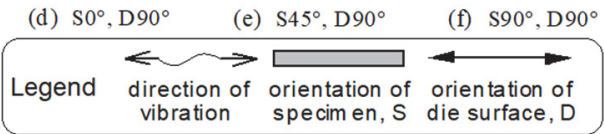

Figure 2 (a) Testing tool; (b) Schematic explanation of movement, specimen orientation and die surface orientation

The driving forces of vibration are produced by a packet of piezoelectric ceramic actuators -7 . The size of actuators is $\varnothing 6 \times \varnothing 12 \times 60 \mathrm{~mm}$. They can generate a movement of about $60 \mu \mathrm{m}$ in magnitude. The movement is transferred to the moving die -10 , through the centring block -9 , which function is to protect the actuators from bending force during upsetting. The springs -13 will store the energies during the first half of cycle of vibration produced by actuators and release them in the second half of the cycle. The required pre-stress for actuators is adjusted by a screw -16. The specimen -11, is positioned between the bottom plate and the moving die. In this tool only the upper surface is subjected to vibration during testing. A laser transducer (KEYENCE LC-2100) measures the vibration. The measured data are transferred to a data acquisition board and HP VEE data acquisition software is used to process the data. 


\section{EXPERIMENTS AND RESULTS}

Aluminium specimens were used for experiments. Three varieties of die surface roughness; two surface orientations and several different vibration parameters were involved in investigations. Schematic location of specimen is shown in Figure 2 a. Hill points out that the theory is not accurate at large deformation in height and so all tests were terminated when reduction reached approximately $50 \%$. Measurements of the length and thickness of the specimen after various reductions form the basis of experimental results. Theoretical predictions are based on initial specimen geometry. Before each test the platens and the specimens were thoroughly degreased and lubricated again. The experiments were performed in the described vibration tool. The experimental strategy was to investigate the influence of different vibration parameters, such as frequency, amplitude, and different roughness and die orientations on friction. Concerning the vibration parameters, $50 \mathrm{~Hz}$ and $100 \mathrm{~Hz}$ of frequency was chosen and $15 \mu \mathrm{m}$ and $20 \mu \mathrm{m}$ in amplitude were selected to study the friction coefficient in a variety of situations. In this study, for the die surface roughness of $R_{a}=0.30$, the dies were ground in a unidirectional way. For the die surface roughness $R_{a}=0.02$ the die surfaces were ground to $R_{a}=0.10$ in both directions and subsequently polished to $R_{a}=0.02$ in both $x$ and $y$ direction.
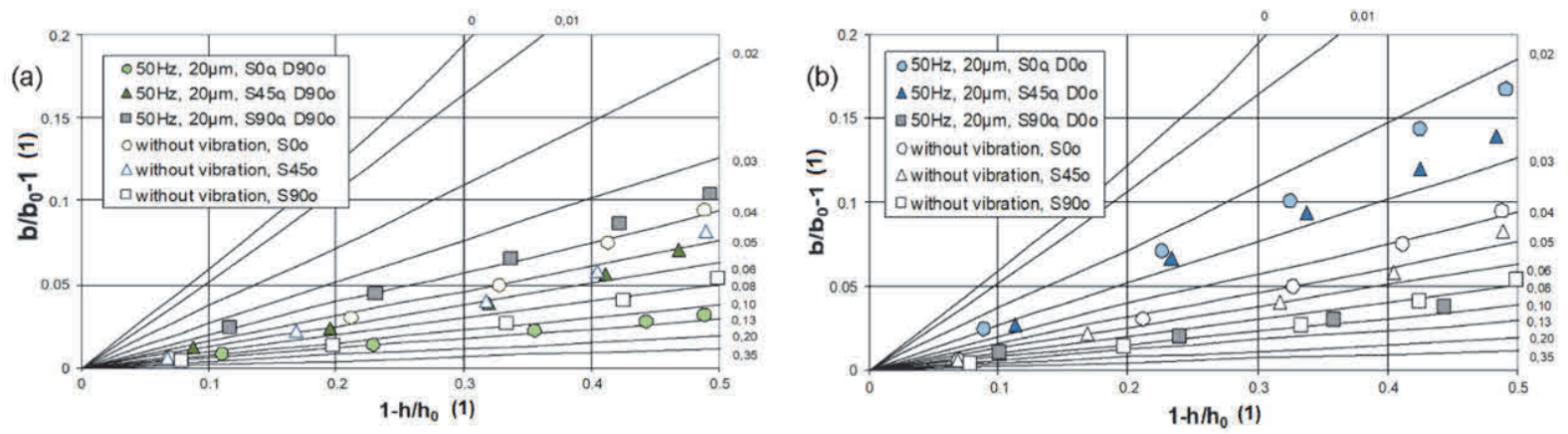

Figure 3 Friction coefficients: (a) die orientation $0^{\circ}$; (b) die orientation $90^{\circ}$

The size of specimen is $30 \times 3 \times 1.5 \mathrm{~mm}$, keeping size ratio to $20: 2: 1$. The specimens were rolled from $3 \mathrm{~mm}$ thick pure aluminium plate and machined to the final size, annealed in the condition of $380^{\circ} \mathrm{C}$ for 3 hours. Specimens were placed in $0^{\circ}, 45^{\circ}$ and $90^{\circ}$ to die surface orientation and upset between two platens, using molykote as lubricant. During upsetting specimen would be taken out to measure the dimensions and relubricate each around every $10 \%$ reduction in height. When vibration applies (Figure 3a), it is easily seen that friction is dramatically reduced compared to the no vibration cases. Comparing three directions of specimen orientation, as well $0^{\circ}$ as $45^{\circ}$ orientations show a decrease of friction compared to the zero vibration case. Friction drops about $45 \%$ for $0^{\circ}$ orientation of specimen and around $40 \%$ for $45^{\circ}$ orientation of specimen. It seems, however that the friction increases somewhat for the $90^{\circ}$ orientation of specimen. This could be explained by the fact that the width direction in this case is in alignment with the $0^{\circ}$ direction, making spread easier and thus reduce the elongation of the specimen. The test (Figure $\mathbf{3 b}$ ) with the die orientation perpendicular to the vibration movements shows some difference in comparison to Figure $\mathbf{3 a}$.
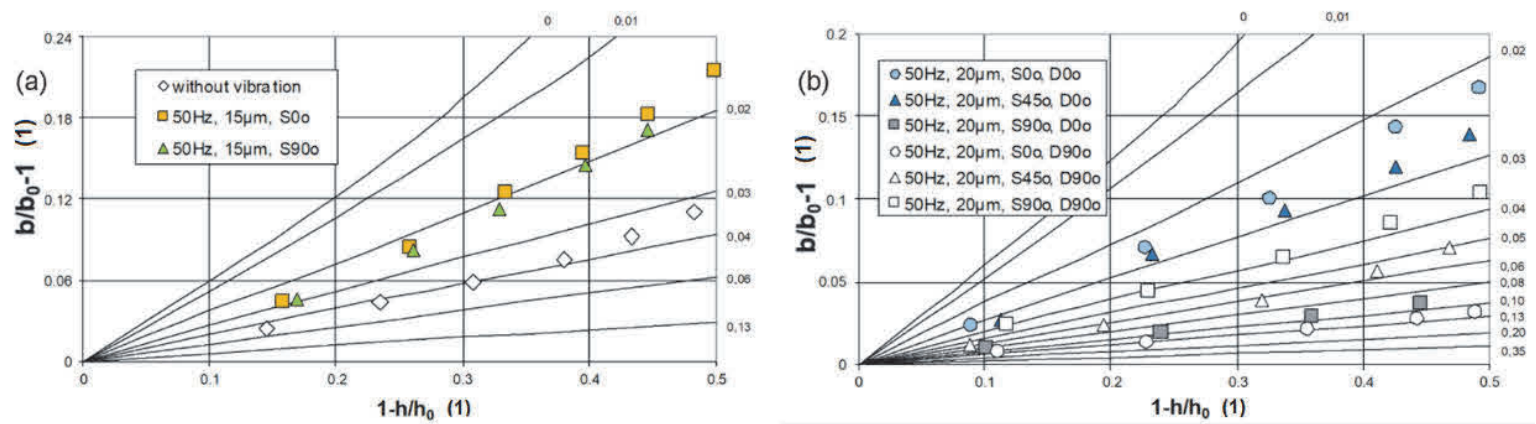

Figure 4 Comparison of two orientations of die for different amplitudes: (a) $20 \mu \mathrm{m}$, (b) $15 \mu \mathrm{m}$ 
In this case, friction is reduced in $0^{\circ}$ and $45^{\circ}$ orientation of the specimens but the effect is not as significant as when the die surface orientation is parallel to the vibration movements. In the case of $90^{\circ}$ orientation of the specimen, friction increases when vibration is applied. Among all tests with different direction of vibration, specimen orientation and die surface orientation the lowest friction happens in the case where the direction of vibration and surface orientation of die have the same direction and specimen was positioned in $0^{\circ}$ direction. The case with the highest friction occurs when direction of vibration and surface orientation of the die are perpendicular and the specimen is oriented in $90^{\circ}$ (Figure 4a). With the die surface roughness about $R_{a}=0.02$, Figure $4 \mathrm{~b}$ shows experimental data derived from upsetting specimens without vibration and with vibration of $50 \mathrm{~Hz}, 15 \mu \mathrm{m}$ of amplitude.
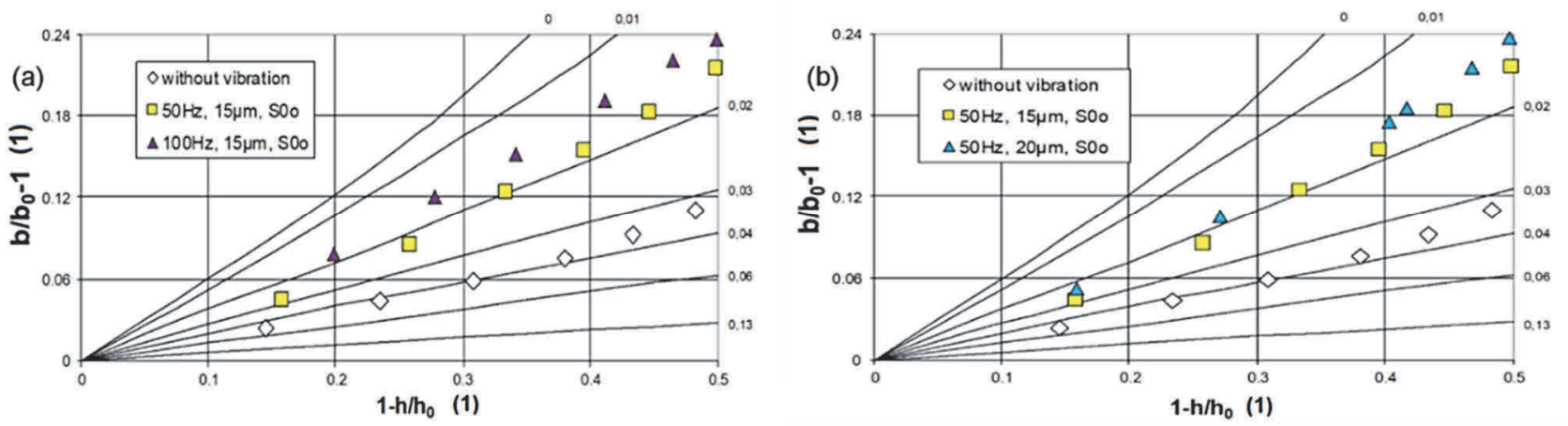

Figure 5 Influence of: (a) vibrations amplitude, (b) vibrations frequency

It seems that friction drops dramatically (nearly 50 percent) in both directions when vibration is applied. Investigation of the role of the amplitude and frequency are shown in Figure $\mathbf{5 a}$ and Figure $\mathbf{5 b}$. From these curves it can be observed that the friction decreases with the amplitude and frequency $(50 \mathrm{~Hz}, 15 \mu \mathrm{m}$ and $20 \mu \mathrm{m}, 100 \mathrm{~Hz}, 20 \mu \mathrm{m})$ increasing. Regarding the influences of vibrating direction to metal flow during compression, all cases showed that the friction is lower when the direction of vibration is the same as the orientation of the specimen.

\section{CONCLUSION AND DISCUSSION}

Experiments with direct mechanical excitation have been carried out with a simplified device. The experimental results verified that this device is satisfactory for the investigations of the influence of vibration on friction in bulk forming.

Experiments show that the orientation of die surface roughness has a strong influence on friction. The difference could be up to more than $40 \%$ between parallel and perpendicular orientation of the specimen, the lowest is found in the parallel case.

\section{REFERENCES}

[1] GARSKIJ, F.K. and EFRONOV, V.I. Effect of Ultrasound on the Decomposition of Solid Solutions, Izv. Akad. Nauk Beloroussk SSR. 1953. vol. 2, pp. 11-16.

[2] BLAHA, F. and LANGENECKER, B. Dehnung von Zink Kristallen unter Ultaschalleinwirkung, Naturwissenschaften, 1955. vol. 42, pp.556-560.

[3] NOSAL, V. and RYMSHA, O.M. Reducing the drawing force by ultrasonic oscillations of the drawplate and determining the technological parameters of tube drawing. Stal. 1966. vol. 2, pp.135-137.

[4] SIEGERT, K. and MOCK, A. Wire drawing with ultrasonically oscillating dies. J. of Materials Proc. Tech. 1996. pp. 657-660.

[5] LEHFELDT, E., Beeinflussung metallischer Reibungsvorgange durch Schall im 20 kHz-Bereich”, Dissertationen RWTH. 1968. Aachen University. 
[6] ROZNER, A. G. Effect of ultrasonic vibration on coefficient of friction during strip drawing. The Journal of the Acoustic Society of America. 1971. vol. 49, no. 5, pp. 20-25.

[7] WESTMACOTT, K. H. and LANGENECKER, B. Dislocation structure in ultrasonically irradiated aluminium. Phys. Rev. Lett. 1965. vol. 14, pp. 15-22.

[8] LANGENECKER, B. Dislocation damping in macrosonic fields. Phys. Rev. 1966. vol. 145, pp. 487-492.

[9] SIDDIQ, A. and SAYED, T. Acoustic softening in metals during ultrasonic assisted deformation via CP-FEM. Materials Letters. 2011. vol. 65, pp. 356-359.

[10] PRESZ, W. and KULIK, T. Ultrasonic vibrations as an impulse for glass transition in microforming of bulk metallic glass. Arch. of Civil an Mech. Eng. 2018. vol. 19, pp.100-113.

[11] SANTOME, Y. and IWAZAKI, H. Superplastic backward microextrusion of microparts for micro-electromechanical systems. J. of Mat. Proc. Tech. 2001. vol. 119, pp. 307-311.

[12] GEIGER, M., KLEINER, M., ECKSTEIN, R., TIESLER, N. and ENGEL, U. Microforming, CIRP Annals - Man. Technology. 2001. vol. 50, no. 2, pp. 445-462.

[13] RAULEA, L.V., GOIJAERT, A.M., GOVAERT, L.E. and BAAIJEN, F.P.T. Size effect in the processing of thin metal sheets. J. of Mat. Proc. Tech. 2001. vol. 115, pp. 44-48.

[14] PRESZ, W. and ROSOCHOSKI A. The influence of grain size on surface quality of microformed components, The 9th Int. Conf. on Material Forming, Esaform 2006, Glasgow, UK, pp. 587-590.

[15] RAN, J.Q., FU, M.W. and CHAN, W.L. The influence of size effect on the ductile fracture in micro-scaled plastic deformation. Int. J. of Plasticity. 2013. vol. 41, pp. 65-81.

[16] PRESZ, W. and ROSOCHOSKI, M. Application of semi-physical modelling of interface surface roughness in design of pre-stressed microforming dies. Int. Conf. on Tech. of Plast., Cambridge, U.K. Pro. Eng. 2017. vol. 207, pp. 4-9.

[17] SALACINSKI, T., CHMIELEWSKI, T., WINIARSKI, M., CACKO, R. and ŚWIERCZ, R. Roughness of Metal Surface After Finishing Using Ceramic Brush Tools. Advances in Materials Science. 2018. vol. 18, no. 1, pp. 20-27.

[18] ŚWIERCZ, R., CHMIELEWSKI, T., SALACINSKI T. and WINIARSKI, M. Surface finishing using ceramic fiber brush tools, In METAL 2017: 26rd Int. Conference on Metallurgy and Materials. Brno: TANGER, 2017, pp. 1222-1226.

[19] PRESZ, W. Contact phenomena in micro-blanking, Int. J. of Material Forming, 2008. vol.1, pp. 471-474.

[20] LIU, S., SHAN, X., GUO, K., YANG, Y. and XIE, T. Experimental study on titanium wire drawing with ultrasonic vibration. Ultrasonics. 2018. vol. 83, pp. 60-67.

[21] ABHISHEC, P., VERMA, C., KRISHNASAMY, H., PANDEY, M., LEE, M.G. and SUWAS, S. Dislocation density based constitutive model for ultrasonic assisted deformation. Mech. Research Comm. 2017. vol. 85, pp. 76-80.

[22] MYSHYAEV, M., SHPEIZMAN, V., KLUBOVICH, V., KULAK, M. and LYU, G. Change in Characteristics of Superplastic Deformation of the Aluminum-Lithium Alloy under the Effect of Ultrasonic Vibrations. Physics of the Solid State. 2015. vol. 57, no.10, pp. 2039-2044.

[23] CHOWDHURY M.A., The wear behaviour of mild steel under vertical vibration. Industrial Lubrication and Tribology. 2014. vol. 61, no 6, pp. 296-300.

[24] PENG, W., HONGJIAN, N., RUIHE, W., WEILI, L. and SHUANGFANG, L. Research on the Mechanism of In-Plane Vibration on Friction Reduction. Materials. 2017. vol. 10, pp. 1015-1036.

[25] CAPOZZA, R., VANOSSI, A., VEZZANI, A. and ZAPPERI, S. Suppression of friction by mechanical vibrations. Phys Rev Lett. 2009. vol. 103, no. 8, pp. 211-219.

[26] TSAI, C.C. and TSENG, C.H. The effect of friction reduction in the presence of in-plane vibrations. Arch. Of Applied Mechanics. 2006, vol. 75, no. 2-3, pp.164-176.

[27] HILL, R. On the inhomogeneous deformation of a plastic lamina in a compression test. Phil. Mag. 1950. vol. 7, no. 41, pp. 733-744.

[28] FRICKER D.C. and WANHEIM, T. Low friction coefficient estimation for model material experiments. Wear. 1974. vol. 27, pp. 303-317.

[29] MUSTER, A. and PRESZ, W., Influence of initial surface roughness on galling behaviour of steel-steel couple, Scandinavian Journal of Metallurgy. 1999. vol. 28, no. 1, pp.5-8. 